Aus dem Bakteriologisch-serologischen Untersuchungsamt der Stadt Altona. (Vorstand: Dr. Zeissler.)

\title{
Die Pferdeblut- oder Schafblut-Traubenzuckeragarplatte als Ersatz fũr die Menschenblut-Traubenzuckeragarplatte zur Züchtung der pathogenen Anaërobier.
}

\section{Von Johannes Zeissler.}

Um Instituten, die nicht genügend Menschenblut zur Verfügung haben, vor allem auch der Veterinärmedizin, das von mir angegehene Züchtungsverfahren (1-6) für pathogene Anaërobier (Fraenkelscher Gasbazillus, Rauschbrandbazillus, Ghon-Sachsscher Bazillus (7), Bazillen des malignen Oedems, Bacillus putrificus Bienstock) zugänglich zu machen, hake ich versucht, das Mens chen blut der MenschenblutTraubenzucker-Agarplatte durch Pferdeblut und Schafblut zu ersetzen. Der Versuch ist gelungen. Die Kulturen der vorgenannten Bazillenarten zeigen auf der Pf erde blut- resp. Schaf blut-Traukenzucker-Agarplatte dasselbe Verhalten wie ich es für die verschiedenen Arten auf der Menschenblut-Traubenzucker-Agarplatte beschrieben babe $(1-4)$. Inskesondere bieten die Kulturen des Fraenkelschen Gasbazillus den charakteristischen Farbenumschlag von Fraisefarben zu Grün, wie er in den Abbildungen zu Eug. Fraenkels Arbeit (5) zu sehen ist, und zwar hängt auch bei Verwendung von Pferdeblut und Schafblut die Farbstoffbildung vom Vorhandensein des Trauben. zuckers at.

Trotz dieser von mir beobachteten Uebereinstimmung im Aus. sehen der Anaërobenkulturen auf den verschiedenartigen Blut-Traubenzucker-Agarplatten (Menschentlut, Pferdeblut, Schafblut) halte ich es im Interesse wissenschaftlicher Genauigkeit für notwendig, in jedem einzelnen Falle anzugeben, von welcher Tierart das dem TraubenzuckerAgar zugesetzte Blut stammt, denn es ist durchaus möglich, daß es (von mir bis jetzt nicht geprüfte) Bazillenarten gibt, deren Kulturen sich verschiedenen Blutarten gegenüber verschieden verhalten. Diese Möglichkeit ist besonders auch dann zu berücksichtigen, wenn etwa Versuche mit dem Blute noch anderer als der kis jetzt von mir herangezogenen Tierarten gemacht werden sollten.

Literatur: 1. D. m. W. 1917. Nr. 28. - 2. Ebenda $1917 \mathrm{Nr} .48 .-$ 3. Zschr. f. Hyg. U. Infektionskrkh. 86. 1918. - 4. M. Kl. $1918 \mathrm{Nr} .24$ - 5. Zbl. rät. I. Abt., Orig. Bd. verfaßten Arbeit beschrieben. 